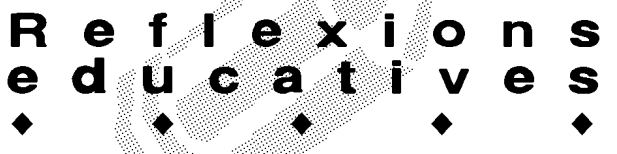

\section{EL TRACTAMENT DELS GRUPS FLEXIBLES D'ALUMNES: BALANÇ D'UNA EXPERIÈNCIA}

\author{
Anna Ferrando Agustí i M. Pilar Julià Tarragó. Mestres del CEIP “Antoni Roig”. Torredembarra.
}

\section{Descripció de la vila i de l'escola}

Torredembarra és una població situada a primera línia de mar i com a vila costanera viu el fenomen d'un constant augment de població. L'impuls turístic de la vila ha induït molts turistes europeus a fixar-hi la seva residència: alemanys, suïssos, anglesos, enlluernats per la bonança climàtica i pel paratge. Aquest impuls ha fet que Torredembarra aculli més del doble de població a l'estiu de la que té habitualment al llarg de l'any, i que es generi un increment de llocs de treball en la construcció $\mathrm{i}$, conseqüentment, una allau de segones residències, majoritàriament procedents de l'àrea metropolitana de Barcelona. Actualment, per la facilitat de comunicacions en la xarxa viària terrestre, aquestes segones residències s'han convertit en primeres vivendes. Aquest augment de la població dels darrers anys, una part de la qual és potencialment reproductora, ha fet crèixer els nivells de la taxa de natalitat, i per tant el nombre d'alumnes del nostre centre és cada vegada més gran. Aquest fet ens ha portat a organitzar l'escola en diferents tipus d'agrupaments.

Una segona causa de l'augment de població escolar s'ha d'atribuir al fet que la vila s'ha convertit en un destacat focus de recepció d'immigrants de diversa procedència. La vila ha absorbit un considerable volum de població d'origen àrab. Alhora, darrerament hi ha hagut un corrent migratori dels països de l'Est d'Europa: romanesos, russos i també xinesos. Més recentment s'ha produït un fort corrent de població provinent del centre i sud d'Amèrica. Aquesta és, per tant, la situació.

EI CEIP "Antoni Roig" de Torredembarra és un centre d'ensenyament primari públic, ubicat a l'antic institut d'ensenyament secundari. És tracta d'un centre espaiós. La disposició del centre és en dues plantes, comptant cadascuna amb un passadís central a banda i banda del qual es distribueixen les aules, totes elles molt lluminoses. Al ser concebut com un edifici per a l'ensenyament secundari, té també uns petits espais que en el seu moment eren els despatxos dels departaments; actualment els anomenem tutories i els aprofitem per poder desenvolupar gran part de la tasca dels agrupaments. El centre compta també amb una biblioteca, dues aules d'informàtica, un menjador, un gimnàs amb els corres- ponents vestidors, una pista exterior poliesportiva i un pati de terra on són ubicades tres aules prefabricades, donat que en aquests moments hem sobrepassat la nostra capacitat. A la façana principal hi ha una de les entrades, al costat hi ha el pati d'Educació Infantil i, a l'altre extrem, l'accés a la vivenda del conserge. El claustre està format pel director i 24 mestres tutors.

El nostre anhel és la pretensió de dur a terme l'educació dels nostres alumnes de forma motivadora aprofitant els recursos que l'entorn ens ofereix i planificant activitats que engresquin els alumnes a sentir-se actius i part integrant de la comunitat, alhora que omplint el ventall de coneixements $\mathrm{i}$ actituds que els podem oferir per gaudir-ne. D'aquesta manera hem anat incorporant al currículum diferents formes d'agrupament, desdoblaments, agrupaments flexibles i moltes altres activitats, algunes de les quals estan dedicades a la natura, com poden ser: I'hort escolar, la recollida de paper per reciclar, l'estudi dels arbres de l'escola, el taller de paper reciclat, el temps, aspectes que recollim en el treball: Un tractament viu del medi ambient, d'aquest mateix número. Això ha permès que els nostres objectius anessin prenent forma, de manera que avui podem oferir als nostres alumnes una educació integral. Aconseguir aquest objectiu no ha estat pas gens fàcil, ja que no sempre ens ha servit la idea inicial que portàvem, bé per la pròpia evolució i dinàmica del centre bé per la validesa o no de la mateixa activitat. Algunes d'aquestes experiències van iniciar-se al curs 1994/95, just el moment en què ens traslladàrem d'un edifici centenari i de gran valor patrimonial per a la vila, que ja no podia satisfer les nostres necessitats com a escola en constant creixement.

\section{Els agrupaments flexibles: com hi entrem}

Els agrupaments flexibles de Matemàtiques són els que fa més temps que duem entre mans. El curs escolar 1994/95 ens plantejàrem aquesta nova forma d'organitzar el centre. El motiu va ser l'assistència a l'escola d'estiu de Tarragona, on un grup de mestres de l'escola "Font d'en Fargas" explicà la seva experiència de treball en grups flexibles. L'experiència ens va engrescar. El curs 1995/96 vam posar fil a l'agulla. Per començar vam demanar un assessorament per poder conèixer $i$ alhora 


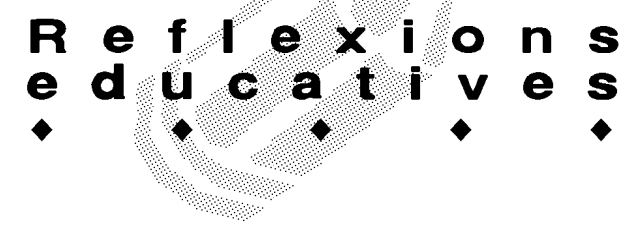

estudiar, per part de tot el claustre, de què es tractava $\mathrm{i}$ com es realitzava el treball amb els agrupaments flexibles. Durant aquell curs vam treballar per veure els avantatges i inconvenients i vam assentar les bases de reflexió sobre l'experiència, tant en una primera fase quan comencéssim com quan es dugués a terme. Vam visitar l'escola del Morell, ja que feia uns anys que hi treballaven i volíem observar sobre el terreny com ho feien.

Amb la informació assumida vam fer un pas més per veure els recursos de què disposava la nostra escola. Així doncs, estudiant la Programació General de Centre, els recursos humans i temporals i el currículum, vam arribar a la conclusió que teníem tot el necessari per provar aquest tipus d'organització de centre i ho vam concretar a l'àrea de Matemàtiques. Des d'aquell moment vam pensar d'una manera diferent en l'horari i en l'organització dels alumnes.

El cur 1996/97 l'escola va començar a funcionar amb agrupaments flexibles. Els vam introduir des de P4 fins a 5 è. Estàvem il-lusionats $i$ alhora amb molts interrogants que en aquell moment encara no podíem respondre. A la fi de curs la valoració fou molt positiva i el claustre va decidir seguir amb l'experiència. Al curs següent ja van funcionar els agrupaments des de P4 fins a 6è. Vam decidir que als grups de P3 no començaríem els agrupaments, ja que pensàvem que el treball d'hàbits i de socialització és bàsic per a una bona integració al grup-classe i els agrupaments hi podrien interferir.

Els agrupaments flexibles: com ens autoorganitzem

Inicialment partírem de la base de definir dos criteris: un el de la distribució dels alumnes i un altre de com fer els canvis de grup. Vegem el primer:

Criteris de distribució dels alumnes

Els alumnes es van distribuir en els diferents grups seguint uns criteris:

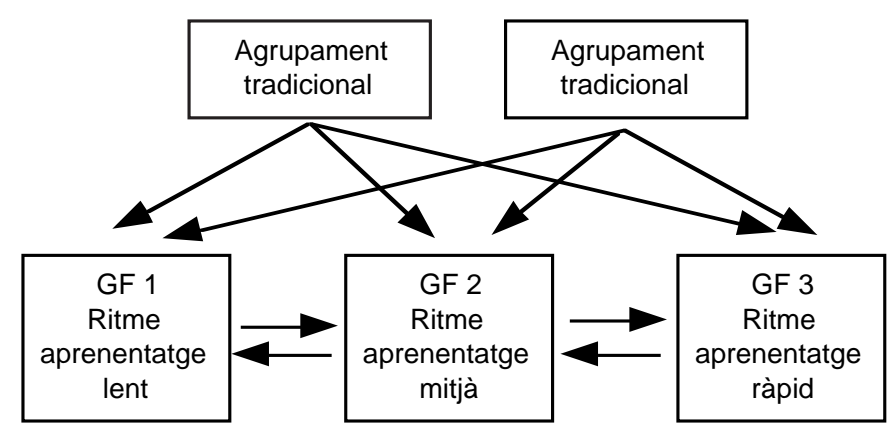

- El primer i el que configura els grups és el ritme d'aprenentatge; els nens es van distribuint des del que agrupa els de ritme més lent fins als de ritme més ràpid.

- Els grups amb el ritme d'aprenentatge lent són els que han de tenir més pocs nens.

- El canvi de grup d'un/a nen/a es fa mitjantçant les sessions periòdiques d'avaluació.

- La nomenclatura dels grups és numerant els grups $1,2,3 \ldots$ començant pel grups de ritme d'aprenentatge més lent.

Criteris de canvi de grup

- El segon criteri va ser definir com canviar de grup.

- Quan el nen/a no segueix el ritme d'aprenentatge del grup on es troba ubicat.

- Quan l'actitud que manifesta no l'ajuda a avançar al ritme que les seves capacitats li permetrien.

- Quan un nen ha faltat molt: absències, malalties... i quan torna a l'escola té buits importants de continguts bàsics: si no els assoleix, difícilment podrà progressar bé en aquests aprenentatges.

Amb aquest plantejament vam analitzar els materials, partint de la base que podien ser utilitzats d'un grup a l'altre, en funció del ritme d'aprenentatge dels nens. Del material en preparàrem un recull tant en l'àmbit d'ampliació dels continguts com en el de reforç. A poc a poc el treballs amb els grups ens dugueren a variar, a pensar en nous materials... El curs 1998-99 acordàrem de fer una bossa de llibres, de manera que els de Matemàtiques es quedessin a l'escola i així aprofitar-los uns cursos abans de canviar-los. Ho vam fer $i$ a la vegada vam ampliar la bossa a altres matèries, però per canvis de les editorials no va funcionar.

\section{Una valoració des de dins}

El curs 2002/03, en fer la valoració dels agrupaments flexibles, vam creure oportú elaborar un Pla Estratègic d'agrupaments flexibles per tal de consolidar la tasca

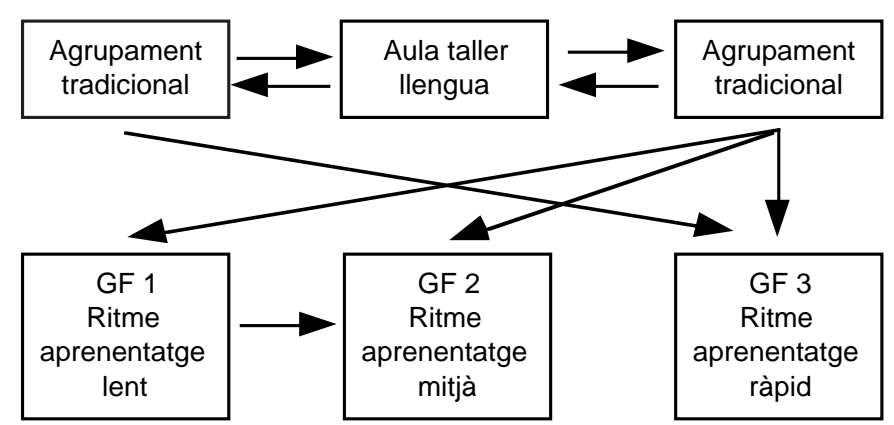

Figura 1. Esquemes dels agrupaments d'alumnes: inicial (esquerra) i actual (dreta) 


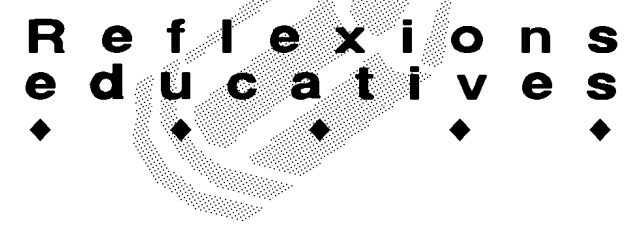

que s'estava portant a terme. Aprovar el Pla ha donat estabilitat a la plantilla, la qual cosa permet fer un seguiment i veure l'evolució dels agrupaments dins la línia educativa de l'escola. Aquest fet també ha comportat una revisió de tots aquells objectius que es van formular en un primer moment a l'hora de plantejar-nos la nova distribució de l'alumnat. L'enfocament segueix essent el mateix en la seva essència: garantir la consecució d'un dret fonamental, basat en el fet que la igualtat d'oportunitats no pot ser ni discriminatòria ni segregadora. D'altra banda, cal matisar que al llarg d'aquests anys l'alumnat de la nostra escola ha variat molt. En el moment d'iniciar l'experiència era un alumnat autòcton, i en algun cas fills d'immigrants de la Península. Per tant, a l'hora de fer la distribució dels alumnes en grups, la premissa a tenir en compte era els diferents ritmes d'aprenentatge.

A l'actualitat Torredembarra és un nucli de població molt heterogeni, en creixement constant i receptor de noves cultures. En moltes ocasions aquest fet ens ha comportat transformar aquella primera premissa, ja que en els nous alumnes hi intervenen factors afegits com és el de la comprensió i expressió de la llengua, que actua de fre en el seu ritme d'aprenentatge. Una vegada superat aquest fre potencial amb suports complementaris, el seguiment és com el de qualsevol altre alumne.

Els esquemes dels agrupaments, tant l'inicial com l'actual, els podeu veure a la figura 1.

El Pla Estrategic ha comportat millores. Se'ns ha dotat d'una aula d'informàtica que permet acostar el treball de l'alumnat al de les noves tecnologies, cada vegada més necessàries a la nostra societat. Conseqüentment, hem fet una redistribució dels mitjans amb què comptem $\mathrm{i}$ hem assignat una hora setmanal (dins l'horari dels agrupaments de Matemàtiques) al treball de Matemàtiques amb ordinador al grup lent, ja que per qüestions de capacitat no podem fer-ho més extensiu. Cal fer esment que dins l'horari estipulat com a classe tradicional es realitza un desdoblament en els cicles mitjà $\mathrm{i}$ superior de Primària en les àrees d'Educació Física-Informàtica, i en el cicle inicial de Primària a l'àrea de Llengua-Informàtica fent-hi treball amb ordinador. També s'incideix en l'àrea de Matemàtiques a educació Infantil amb Expressió Oral i Informàtica. D'aquesta manera, tothom té accés als mateixos mitjans, aspecte que sempre tenim present.

Les innovacions en el nostre projecte requereixen una revisió constant dels recursos del centre, siguin espacials, temporals o humans, a fi de poder tirar-lo endavant. Implica també una actualització de les noves tecnologies per part de la coordinadora d'informàtica i una bona coordinació amb l'equip de mestres per compartir la informació. Per tal que aquest sistema funcioni cal fer una avaluació periòdica del treball efectuat, valorar els programes treballats i sospesar si eren adients als nostres propòsits, o al contrari, els hem de descartar. Quan agrupem l'alumnat seguint el criteri dels diferents ritmes d'aprenentatge, hem d'ésser conscients de donar resposta a les necessitats de cadascun dels grups formats: emprar metodologies adequades als diferents grups, realitzar activitats diferenciades, buscar recursos i suports que no són pròpiament matemàtics, etc. per tal de poder desenvolupar les diferents capacitats a través del treball dels continguts i assolir els objectius proposats.

Hem de fer també reflexió sobre el tipus de treball que estem realitzant amb els grups d'alumnes i interioritzar bé el concepte de grup flexible per promocionar els alumnes d'un grup a un altre segons els criteris establerts prèviament. Hem de crear grups amb mobilitat. No deixar-los estancats, ja que això ens indicarà un greu error en la concepció del nostre treball. Els avantatges i desavantatges que hi trobem, els explicitem finalment en el darrer apartat, considerant que els primers són superiors als segons.

\section{Avantatges i inconvenients dels agrupaments flexibles} Avantatges:

- Reducció del nombre d'alumnes.

- Treball més individualitzat, on es poden sentir més estimulats.

- Més perspectives d'èxit en l'aprenentatge.

- Augment de l'autoestima.

- Coneixement més personal dels alumnes.

- Ampliar el ventall de relació personal.

- Motivar-se tot tenint un ritme d'aprenentatge ràpid.

- Avançar segons les necessitats individuals.

- Implica una necessària actualització personal per part del professorat, i això comporta satisfacció i benestar.

Inconvenients:

- És necessari disposar de molts espais.

- És difícil confegir els horaris del professorat.

- El grup de ritme d'aprenentatge lent pot perdre expectatives de progrés.

- Caure en la "inflexibilitat" del grup. 